Short Report

\title{
The Relation between Experimentally Induced Pyelonephritis and Hypertension
}

\author{
Seigi Tsuchida, Osamu Yamaguchi, Shigeru Arai* and \\ SoITsu FuKuChI $\dagger$ \\ Department of Urology, Akita University School of Medicine, \\ Akita, First Department of Pathology, ${ }^{*}$ Yamagata University \\ School of Medicine, Yamagata, and Second Department of \\ Internal Medicine, $\uparrow$ Tohoku University School of Medicine, \\ Sendai
}

Tsuchida, S., Yamaguchi, O., AraI, S. and Fuguchi, S. The Relation between Experimentally Induced Pyelonephritis and Hypertension. Tohoku J. exp. Med., 1975, 115 (4), 393-394-Hypertension resulting from chronic pyelonephritis has been shown in clinical as well as experimental cases, although some authors deny that there is a pathogenic relationship between the two. To throw light on this problem the present authors conducted a series of experiments with mongrel dogs, in which chronic pyelonephritis was induced and postoperative changes in blood pressure and plasma renin activity were observed over a period of 3 months. The pyelonephritis infection was brought about by a method involving vesicoureteral reflux and ureteral dysfunction, as described in a previous paper. Preoperative and postoperative levels of systolic pressure were compared, but no definite trends were found for the first 3 weeks after operation. At 30,60 and 90 days the pressures were found to have risen by $21.2 \pm 11.2 \mathrm{mmHg}, 21.7 \pm$ $14.6 \mathrm{mmHg}$ and $17.1 \pm 16.7 \mathrm{mmHg}$, respectively. Thus there was a significant elevation $(p<0.01)$. No appreciable change in the plasma renin activity was found, however, at any stage. From these results it was concluded that experimentally induced chronic pyelonephritis in dogs caused a rise in blood pressure. No connection between the pyelonephritis and the renin angiotensin system was found. - experimental pyelonephritis; hypertension; plasma renin activity

The clinical relationship between chronic pyelonephritis and hypertension was early noted by Longcope (1937) and Weiss and Parker (1940). Experimentally, Spitznagel and Schroeder (1951) induced pyelonephritis unilaterally in 16 rats by partial ureteral constriction and intravenous injection of $E$. coli, and confirmed resultant hypertension in 9 cases. Some authors, however, have doubted that hypertension is caused by experimentally induced chronic pyelonephritis. In the present study, the authors induced ureteral dysfunction in 30 adult mongrel dogs to produce chronic pyelonephritis and observed changes in both blood pressure and plasma renin activity for a long period after operation. The method of causing infection through vesicoureteral reflux and ureteral dysfunction was described in a previous paper (Tsuchida et al. 1973).

Postoperative levels of blood pressure, plasma renin activity and plasma sodium were measured over periods ranging from 3 weeks up to 220 days at the maximum. Seven animals died within 3 weeks of operation; the remaining 23 were available for statistical tabulation. Measurements of blood pressure were carried out by cannulating the femoral

Received for publication, November 21, 1974.

* Director: Prof. S. Arai.

+ Director: Prof. K. Yoshinaga. 


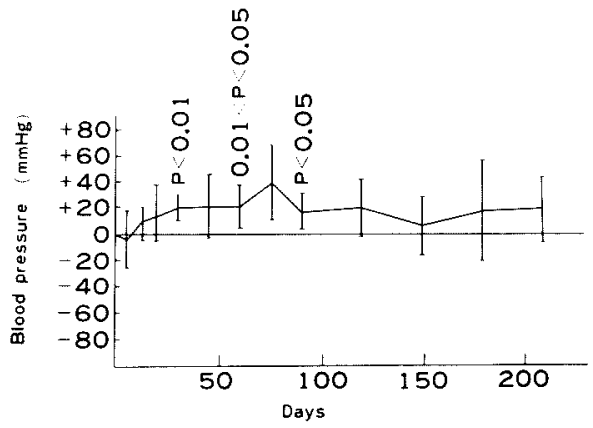

Fig. 1

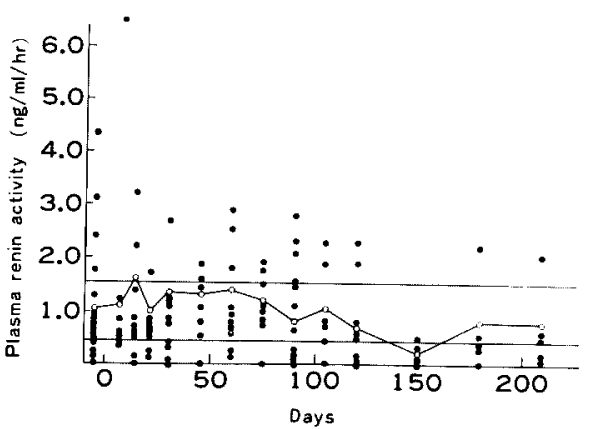

Fig. 2

Fig. 1. Postoperative changes in systolic blood pressure.

Fig. 2. Postoperative changes in plasma renin activity.

artery under anesthesia with sodium pentobarbital. Plasma renin activity was determined by radioimmunoassay. The findings are summarized below.

Changes in blood pressure

Preoperative levels of femoral arterial systolic pressure averaged $156 \pm 7.5 \mathrm{~mm} \mathrm{Hg}$. Postoperative changes were obtained by comparing blood pressure levels before and after operation. An average for pressure changes in 23 dogs was obtained at each stage of measurement (Fig. 1). The significance of the changes in blood pressure was checked by the Student $t$ test. From 7 to 21 days after operation the levels fluctuated. At 30 , 60 and 90 days, the elevations averaged $21.2 \pm 11.2 \mathrm{mmHg}, 21.7 \pm 14.6 \mathrm{mmHg}$ and 171.1 $\pm 16.7 \mathrm{mmHg}$, respectively. The elevation was statistically significant $(p<0.01)$. At 120 to 210 days, with only 8 animals surviving, a statistical test could not be made, but the average blood pressure levels were still rising.

Changes in plasma renin activity

The average preoperative level of plasma renin activity in the dogs was $1.00 \pm 0.54$ $\mathrm{ng} / \mathrm{ml} / \mathrm{hr}$. The average postoperative level at each stage of measurement is shown in Fig. 2. The data indicate that plasma renin activity did not change significantly at any stage. Plasma sodium concentration was also measured throughout the period, but no significant changes were observed.

In the present experiments, blood pressure fluctuated up to 3 weeks after operation. From around 30 days, however, blood pressure apparently rose continuously for more than 90 days. We previously reported that the inflammation became stable [within 30 days after the procedures for inducing pyelonephritis (Tsuchida et al. 1973). The apparent coincidence in time between the manifestation of chronic inflammation and the start of rise in blood pressure may indicate a direct relation between the chronic pyelonephritis and the hypertension. The finding that plasma renin activity did not change during the period of observation suggests that it does not contribute to the initiation of the hypertension.

\section{References}

1) Longcope, W.T. (1937) Chronic bilateral pyelonephritis, its origin and its association with hypertension. Ann. intern. Med., 11, 149-162.

2) Spitznagel, J.K. \& Schroeder, H.A. (1951) Experimental pyelonephritis and hypertension in rats. Proc. Soc. exp. Biol. Med. (N.Y.), 77, 762-764.

3) Tsuchida, S., Sugawara, H. \& Arai, S. (1973) Ascending pyelonephritis in dogs induced by ureteral dysfunction. Invest. Urol., 10, 450-457.

4) Weiss, S. \& Parker, F., Jr. (1940) Relation of pyelonephritis and other urinary tract infection to arterial hypertension. New Eng. J. Med., 223, 959-967. 